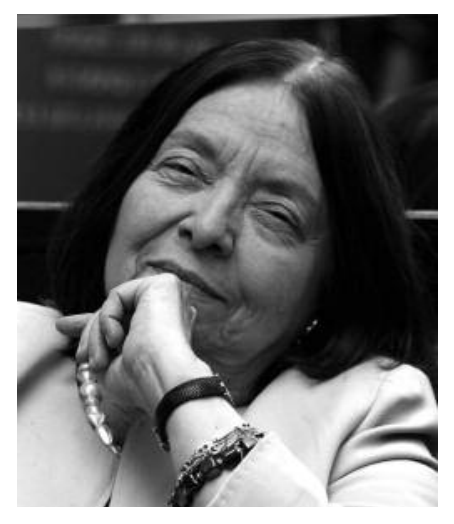

NÉlida PiÑón. Río de Janeiro (1937). Licenciada en Periodismo por la Universidad Católica de Río de Janeiro y en Filosofía por la Universidad de Columbia. Es una de las figuras más destacadas de las letras latinoamericanas contemporáneas. Sus obras están traducidas a varios idiomas y se han publicado en más de veinte países. Debutó como novelista en 1961 con Guía-mapa de Gabriel Arcanjo, a la que siguieron Madera hecha cruz (1963), Fundador (1969), La casa de la Pasión (1972), Sala de armas (1973), Tebas de mi corazón (1974), La fuerza del destino (1977), el libro de relatos El calor de las cosas (1980), La república de los sueños (1984) y Voces del desierto (2004), estas dos últimas publicadas en España por la editorial Alfaguara. En 1995 le fue otorgado el prestigioso premio latinoamericano Juan Rulfo y en 2005 el Príncipe de Asturias de las Letras por «su incitante obra narrativa, artísticamente sustentada en la realidad y la memoria y también en la fantasía y los sueños». Próximamente publicará el libro de ensayo Aprendiz de Homero y un libro de aforismos y memorias que lleva por título Corazón andariego. 


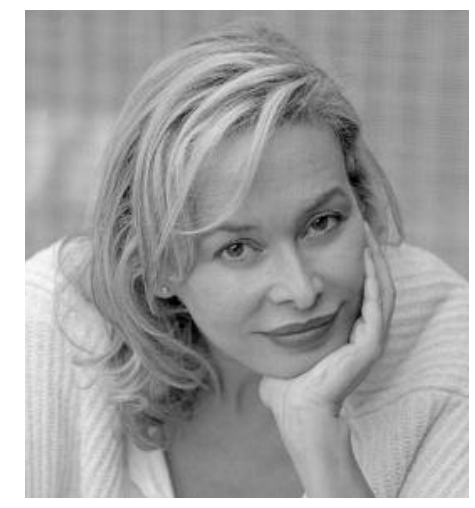

SUSANA ForTES. Pontevedra (1959). Es licenciada en Geografía e Historia por la Universidad de Santiago de Compostela y en Historia de América por la Universidad de Barcelona. Con su primera novela, Querido Corto Maltés, ganó en 1994 el Premio Nuevos Narradores; en 2001 fue finalista del Premio Primavera, convocado por la editorial Espasa, con la novela Fronteras de arena. Además ha publicado Las cenizas de la Bounty (1998), Tiernos y traidores (1999) y el cuaderno de cine Adiós, muñeca (2002). En 2003 fue finalista del premio Planeta con la novela El amante albanés, que ha conseguido en EE.UU. el tercer premio «2006 Book of the Year Awards». Posteriormente, su novela El azar de Laura Ulloa (Planeta, 2006) recibió el Premio de la Critica concedido por la Asociación de Escritores y Críticos de la Comunidad Valenciana. Hasta la fecha sus obras han sido traducidas a numerosos idiomas. Los derechos internacionales de su última novela publicada recientemente en España, Quattrocento, ya han sido vendidos hasta el momento a más de quince países. Colabora habitualmente en el diario El País, así como en revistas de cine y literatura. 


\title{
LAS PATRIAS SECRETAS DE NÉLIDA PIÑÓN
}

\author{
SUSANA FORTES
}

\begin{abstract}
RESUMEN
Brasileña de ascendencia gallega, Nélida Piñón es una de las voces más interesantes de la literatura contemporánea. En ella confluyen diversas tradiciones literarias que configuran una personal teoría del mestizaje, donde la memoria se mezcla con la fantasía y los sueños. El éxito no la ha cogido de brazos cruzados. Agradece el reconocimiento y los premios con franqueza, pero su propia ironía la mantiene a salvo de la vanidad. Polisémica, camaleónica, Tauro con ascendente Sagitario, tierra y fuego, optimista, comprometida, enamorada de Homero... Su obra representa un diálogo inteligente y vivificante entre los dos lados del Atlántico. El portugués es el idioma de su alma y narrar viene a ser para ella un acto fundacional, por eso no concibe que «alguien pueda volver a su casa o a su falsa modernidad sin llevar en el corazón o en el bolsillo un pequeño relato».

$\Rightarrow$ PALABRAS CLAVE: narrativa brasileña, Galicia.
\end{abstract}

Conocí a Nélida Piñón en el invierno de 2005 en un homenaje que le brindó el ayuntamiento gallego de Cotobade, nombrándola hija adoptiva en honor a los dos años que pasó de niña en la aldea de Borela, de la que procedía su familia. Después de la entrega de premios y de los discursos institucionales de rigor, la reunión acabó, como suele ocurrir en Galicia, con una cena de amigos en una casa de campo con chimenea encendida, bacallao a la teja y filloas caseras rellenas de nata. Fue entonces, en los postres, cuando la escritora dio rienda suelta a una vena narrativa y humorística en la mejor línea de la tradición oral que une como una corriente poderosísima la literatura a los dos lados del Atlántico. En medio del aguacero que azotaba las ventanas, su voz pasó a formar parte de la 
lluvia como una retahíla entreverada de cuentos, historias, anécdotas... Esa sustancia misteriosa que borbotea en las cocinas de las casas, porque en los sociedades rurales la cocina ha sido siempre el lugar donde se habla, donde se recuerda a los que no están, a los que emigraron, donde se resuelven problemas, donde se cuece el caldo de la vida. Ese primer sustrato narrativo es sin ninguna duda el germen de toda la escritura de Nélida Piñón, que como la princesa Sherezade, cuyo mito recrea en la novela Voces del desierto, es capaz de deshacer los nudos de la mortalidad.

Apenas tenía diez años cuando llegó por primera vez a Galicia y nada más bajar del barco, debió de sorprenderle el aura de aquella tierra de huertos pequeños, encapotada de nubes, con mujeres vestidas siempre de negro que iban enlazando unos muertos con otros. Ella que venía de la luz y de la naturaleza exuberante... «No me gustó el gallego -reconoció-». Me pareció arisco, áspero como el vino verde, el vino de aguja. Pero luego me llevaron a la aldea de mi padre. Llegamos con maletas y maletas. Llovía y pasamos por un puente. Todo estaba lleno de barro, entonces miré el puente y una capillita que había a un lado del camino y creo que fue en ese momento cuando empecé a enamorarme de aquel nuevo mundo. Tuve la sensación de que iba a amar Galicia para siempre».

Diez años es la edad en la que empiezan a establecerse los fundamentos del imaginario. Quizá fue entonces cuando Nélida Piñón se dejó impregnar por ese sentimiento tan gallego de la memoria y de lo sobrenatural, del sentido panteísta de la tierra, del paso de las estaciones y la pasión por los tiempos pretéritos que aparece en todas sus novelas. Por supuesto ése no es el único fermento de su literatura, que está recorrida por otras muchas corrientes, como un río mestizo en el que cabe desde la alquimia de los druidas celtas 
hasta el espíritu de los filósofos grecolatinos o el sueño de los poetas árabes. También la herencia africana, la hebrea y la de todas las civilizaciones que pasaron por tierras brasileñas: portugueses, españoles, holandeses... Porque la literatura no se puede separar de la vida ni de la historia, y como ella misma dijo alguna vez: «Las patrias son muchas y exceden el lugar en el que nacimos, son patrias secretas que no tienen nombre, pero que nos simbolizan». Muchas veces la patria son los libros y los escritores que una admira: Cervantes, Garcilaso de la Vega, Unamuno, Ortega y Gasset, Joâo Guimaraes Rosa, la escritora Clarice Lispector, a quien le unía una verdadera amistad y sobre todo, Machado de Assis, ese otro gran escritor brasileño por quien Nélida Piñón manifestó siempre una admiración profundísima. «Lo considero un genio -afirmaba recientemente en una entrevista-. Me emociona que haya existido. Siempre digo una frase que sigue teniendo vigencia: Si Machado de Assis existió, Brasil es posible. No hay pretextos para el fracaso en un país que ha generado y engendrado un hombre como él.»

Yo creo que esto mismo podría decirse también de Nélida Piñón, una escritora que se considera a sí misma como la última mohicana, porque es el último eslabón de su familia y que, cuando empezó a escribir lo tenía todo en contra: era muy joven, mujer y brasileña. El portugués era una lengua minoritaria y no existía un puente entre Brasil y Europa, como ocurría por ejemplo con los escritores hispanoamericanos del boom, que tenían la ventaja del idioma, del poder literario y de los nombres ya implantados que ella nunca tuvo. Sin embargo mantuvo una fidelidad inquebrantable al portugués al que considera mucho más que un idioma. «Siempre sentí que tenía una deuda moral y afectiva con la lengua -dice-. Soy una mujer absolutamente enamorada del portugués. Es 
mi dominio, mi territorio». Desde luego no debió de ser fácil bajo una dictadura, ni en un país tan pobre como era el Brasil de su juventud, pero logró abrirse paso en esas condiciones. Fue la primera mujer que presidió una academia de la lengua en todo el mundo -A Academia Brasileira das Letras-, además es miembro de la Academia de las Ciencias de Lisboa y de la Academia de Filosofía de Brasil. Resultó distinguida como doctora honoris causa por diversas universidades y se convirtió en una de las voces narrativas más interesantes de la literatura contemporánea. Cultivó todos los géneros: relato, novela, teatro, crítica, ensayo... Recibió importantísimos premios literarios, como el PEN Club, en 1985, el Premio Principe de Asturias de Las Letras, en 2005, o el Juan Rulfo, que viene a ser como el Nobel hispanoamericano, por La República de los sueños, probablemente su mejor novela. Una auténtica épica de la emigración, inspirada en la experiencia de sus abuelos, en la que los protagonistas, Madruga y Venancio, se conocen en 1913, siendo casi unos niños, durante el trayecto de Vigo a Río de Janeiro, a bordo de un barco inglés que los llevaba, como a tantos otros, desde la miseria de su Galicia natal hacia otro mundo fascinante en busca de un sueño. Los sueños están hechos de emociones, de esfuerzo, de sentimientos, pero también de derrotas íntimas, y $L a$ República de los sueños es ese lugar donde todas las esperanzas humanas pueden cumplirse. A fin de cuentas el triunfo y el fracaso no son más que los dos polos de cualquier epopeya.

Una enseñanza ésta que seguramente Nélida Piñón tiene grabada a fuego en la memoria, porque fue precisamente el mensaje que le transmitió su madre, a quien la escritora se sentía especialmente unida, antes de morir: «Hija, estoy contenta con tus caminos, pero no hablo de la profesional, de la que gana premios y doc- 
torados honoris causa... Hablo como ser humano, cada vez más compasiva y más alejada de las vanidades de la profesión».

Nélida Piñón no suele citar a grandes sabios, ni a intelectuales, ni a escritores. Sin embargo habla mucho de su familia. Nombra con frecuencia a su abuelo, Daniel, a su padre, a su madre, Carmen, tal vez porque siente que de verdad fueron ellos quienes le concedieron un estatuto moral con el cual ha ido construyendo su propio ideario íntimo y literario. «Cada vez recuerdo más lo que decían. Voy almacenando frases, las guardo en el armario junto con los mejores trajes. Entre las mejores alhajas de mi familia están las palabras.»

Este año volví a encontrar a Nélida Piñón en Santa Cruz de Tenerife en un congreso sobre Mujer y Literatura. Cenamos la última noche en el restaurante del hotel con la escritora Cristina Sánchez-Andrade. Hay una fotografía de las tres en franca hermandad galaico-portuguesa, brindando sobre los manteles blancos de la madrugada por su último amor: un perro huérfano de ojos biafreños, llamado Gravetinho, que significa «astilla».

La mirada de Nélida Piñón, es exótica, sonriente, una mirada viajera, que va de aquí para allá, elegante, generosa. La manera de mirar es también la manera de pensar y de enfrentarse al mundo o de adelantarse a él. Desde luego la suya no es la mirada de alguien que escribe desde una torre de marfil, sino desde el puro centro de la vida. Puede que Nélida Piñon haya tenido una formación clásica, casi aristocrática, pero es sobre todo una mujer moderna, interesada por todo cuanto sucede a su alrededor, comprometida con la vida y con la literatura. Probablemente la escritora estuviera ya en aquel momento enredada en algún pensamiento de su próximo libro, un ensayo que está a punto de publicar y cuyo título la identifica quizá mejor que ningún otro: Aprendiz de Homero. 